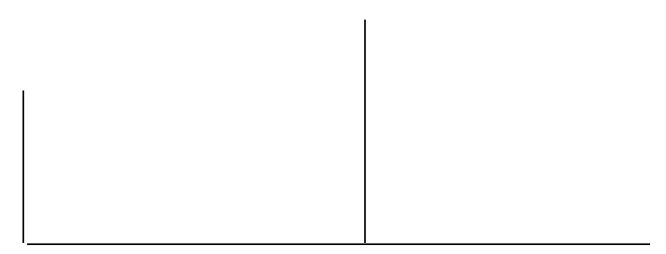

Rev. Latinoam. Psicopat. Fund., IX, 3, 410-422

\title{
O pharmakon na interface do dispositivo analítico: o pathos na busca de sua verdade
}

\author{
Ana Irene Canongia
}

\begin{abstract}
O artigo é um convite à problematização da indicação do medicamento antidepressivo e, portanto, do diagnóstico e do papel do psiquiatra como o estranho-familiar na relação psicanalítica ou na relação psicoterápica de base psicanalítica no tempo urgente da atualidade. Apresenta resumidamente as últimas contribuições sobre o diagnóstico abrangente, idiográfico, e utiliza duas vinhetas clínicas com a finalidade precípua de ilustrar o pathos antes e depois da utilização dos psicofármacos.
\end{abstract}

Palavras-chave: Pharmakon, diagnóstico abrangente, interface, pathos 
Este artigo é um convite à problematização da indicação, da introdução e do uso do medicamento (antidepressivo) e, portanto, do diagnóstico e do papel do psiquiatra como o estranho-familiar na relação psicanalítica ou na relação psicoterápica de base psicanalítica. Para tanto, apresenta resumidamente as últimas contribuições sobre o diagnóstico abrangente (comprehensive diagnosis), como forma de vislumbrar uma reconfiguração da maneira reducionista do clinicar que prevalece no tempo urgente da atualidade. As duas vinhetas clínicas utilizadas servem, no momento, mais para ilustrar o pathos antes e depois da utilização dos psicofármacos do que para aprofundar a discussão sobre o funcionamento psicodinâmico.

Podemos iniciar com Freud (1930a[1929]) que tão bem afirmou que o homem, cujo objetivo é perseguir a felicidade, vai enfrentar a infelicidade pela substituição, pela intoxicação, pela diversão. Logo, é possível depreender-se a atualidade dessa constatação.

O funcionamento pathico contemporâneo caracteriza-se pela cultura do descartável, do consumo desenfreado, do que é performático diante do olhar absoluto do outro, da pressa de "fazeres", do horror ao envelhecimento, posto que este não mais representa a sabedoria, como nos tempos idos: resta a Verleugnung. O olhar que substituiu a voz não permite que se fale para o outro como outro diferente de si mesmo; não há tempo, não há escuta.

Como pathos é efeito de encontros, sendo o primeiro deles aquele conseqüente à experiência primária com o outro materno, tem-se que o pathos, patológico ou não, como sofrimento, traz em si a dimensão de um ensinamento desde que possa ser ouvido por um outro, estranho a si, mas não indiferente, portador de Eros que esteja legitimamente interessado na singularidade do pathos. Dito de outro modo, a ética desse interesse não deve ser precipuamente aquela do querer confirmar tanto as próprias teorias sobre o adoecimento e as indicações terapêuticas, quanto incrementar estatísticas ou aplacar a própria angústia diante do não saber. 


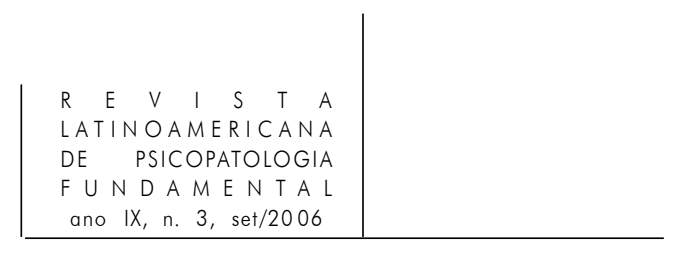

Como, então, exercer o clinicar - que é o inclinar-se para melhor compreender - nos dias atuais, onde observamos, entre as características acima citadas, a mudança da temporalidade? O tempo é o do agora, predomina o presente imediato. Sem pausa ou intervalo, tão necessários para constituir um antes e um depois, a dimensão do amanhã se evanesce. Consoante com esse funcionamento do não-tempo, a pressa impera. Testemunhamos o incremento das condutas terapêuticas tecnicistas, impessoais, como resposta ao "encontro clínico", não só na psiquiatria, mas em outras especialidades médicas. O que fica patente é a resposta terapêutica baseada unicamente no conjunto de sinais e sintomas classificados num sistema nosológico ordenado, e o empobrecimento da relação humana com o paciente. O sofrimento é tomado como estatística, opera-se o divórcio entre o corpo e a mente.

Esta é a clínica baseada em evidências, cuja resposta deve ser a pronta eficácia. Não há margem para a dúvida, o não saber ou o adiamento, é a clínica da certeza.

Aqueles que buscam nossa ajuda desejam respostas eficazes para o alívio das suas dores, sejam elas físicas, da alma, ou morais. Sem dúvida é preciso trabalhar na direção da cura, do alívio, caso contrário nós não seríamos profissionais da saúde, mas numa outra lógica, qual seja aquela que leva em conta a integralidade do sujeito em sofrimento, a singularidade do adoecimento. É possível inferirmos que essa lógica pode fazer parte das evidências, sem contudo ser contraditória com a própria definição de evidência já que, se levarmos em conta a historicização, o contexto, o singular, eles podem tornar claro, manifesto, evidente, o pathico patológico.

Sabemos que o aparelho psíquico é um aparelho de defesa que integra o sistema imunológico. Este aparelho permite ao humano enfrentar o medo da perda do contato com a regularidade, e a depressão pela perda do objeto de satisfação (Berlinck, 2000, p. 15). Ou seja, diante da adversidade do ambiente que gera o desamparo, surge a necessidade de uma "certa proteção".

Como dito acima, na urgência contemporânea pode não haver tempo "fisiológico" para que o aparelho de defesa dê conta do vazio existencial. Abrese então o caminho para o comportamento adictivo como resposta a essa falência. A utilização indiscriminada dos medicamentos antidepressivos e ansiolíticos serve bem a essa lógica adictiva e substitutiva do vazio de si mesmo, já que tanto o sujeito que exerce a clínica quanto aquele que está em sofrimento são regidos necessariamente pela lógica do coletivo, do social do qual fazem parte.

Nessa medida confrontamo-nos com a árdua tarefa de conciliar no encontro clínico tanto a possibilidade de ele ser o lugar onde a experiência subjetiva da doença possa ser narrada, compreendida e contextualizada, quanto a urgência do tempo e a expectativa da resposta imediata, eficaz como resultado. 
O diagnóstico, melhor dizendo, o processo diagnóstico, é a pedra de toque tanto da psiquiatria quanto da psicanálise, pois sem o mesmo não é possível instituir-se a terapêutica. No entanto, é necessário que a dimensão do vivido seja contemplada na sua tessitura. Dito de outro modo, são as "marcas e relíquias do vivido" (Saurí, 2001, p. 47) que dão a dimensão de próprio, de singular, na atribuição do valor.

Dentre as muitas definições da palavra valor no Dicionário Houaiss, está aquela do "reconhecimento, do ponto de vista afetivo, da importância ou da necessidade de algo ou de alguém".

A noção de valor tem relevância para o diagnóstico psiquiátrico, razão pela qual trava-se atualmente, em âmbito mundial, amplo debate sobre a dimensão dos valores (Mezzich, 2005, p. 91) em função do IGDA.

O IGDA (Guia Internacional de Avaliação Diagnóstica/2003) é uma nova modalidade de classificação diagnóstica abrangente, isto é, ela inclui dois componentes para o seu uso: uma formulação diagnóstica padronizada e uma formulação idiográfica. Resulta de uma força-tarefa iniciada em 1994 pela Seção de Classificação e Diagnóstico da WPA (World Psychiatry Association). É constituída por especialistas de várias nacionalidades e de diferentes correntes teóricas e fornecerá elementos e subsídios para a CID-11 (Pereira, 2004, p. 15). Com essa mesma abordagem, temos o recente GLADP (Guia Latino-americano de Diagnóstico Psiquiátrico/2004) produzido pela Associação Psiquiátrica Latinoamericana que é uma adaptação regional da CID-10 (Sadock, B. \& Sadock,V., 2005, p. 1045 e 1049).

O que é relevante nessas classificações é a valorização da dimensão idiográfica do diagnóstico. O que vem a ser a dimensão idiográfica? Idios, do grego, significa o que é próprio, especial, e graphein quer dizer escrever. Tratase, portanto, de uma abordagem singularizada do paciente, que leva em conta o contexto subjetivo e biopsicossocial do qual emerge o seu sofrimento psicopatológico. Mas, cabe ressaltar, há o risco potencial de essas classificações diagnósticas que são multiaxiais desvirtuarem-se de sua proposta inicial. Afinal, os atuais sistemas classificatórios, a CID-10 e DSM-IV TR, ${ }^{1}$ por exemplo, contam também com o diagnóstico multiaxial, sendo na primeira o eixo III - o que trata dos fatores contextuais - e na segunda o eixo IV, - que aborda o funcionamento global. No entanto, os dois sistemas revelaram-se, em sua utilização, sistemas 


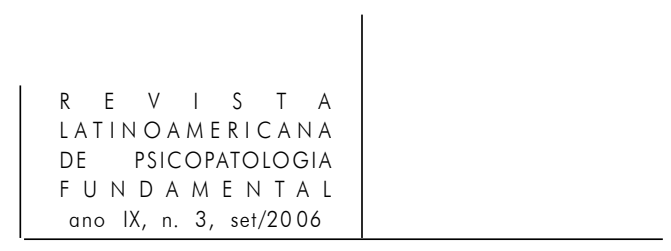

operacionais reducionistas e normativos. Mas sejamos otimistas: afinal, com a perspectiva abrangente, a clínica pode ser revalorizada nos futuros sistemas classificatórios.

Para esse modelo de processo diagnóstico, cuja noção de valor está presente nos diversos eixos do diagnóstico multiaxial, tornam-se relevantes aspectos tais como contexto, cultura, subjetividade e historicização. As noções de "sentido", "significado" e "compreensão" ganham relevo como elementos de valor no dizer, na linguagem do sujeito em sofrimento - sofrimento que não é só aquele decorrente dos transtornos mentais. Essa atitude deve ser extensiva à medicina como um todo, e não prerrogativa da psiquiatria e da saúde mental.

Não é demais repetir que temos a difícil tarefa de reencontrar o tempo necessário, ainda mais que na modalidade do diagnóstico abrangente, o tratamento e a promoção da saúde devem estar centrados nas necessidades e nas metas do paciente, o que requer também a constituição e construção de um vínculo, seja para o processo de diagnóstico, seja para a própria terapêutica e a indispensável adesão do paciente. Disto resulta que o profissional de saúde precisa se interrogar, por exemplo, sobre se o que tem para oferecer é aquilo que o paciente necessita, se é possível atendê-lo na sua demanda, o que é que ele, paciente, considera retorno à "normalidade", quais as suas legítimas expectativas.

Como é possível depreendermos, a dimensão valorativa se faz presente em todas as etapas da abordagem clínica. Por exemplo, valores têm grande importância no eixo IV (qualidade de vida) que integra o IGDA que tem quatro eixos na sua formulação axial, além da formulação idiográfica com três eixos, assim como no GLADP que também tem uma formulação multiaxial e uma idiográfica.

Aceita-se amplamente que o acesso à qualidade de vida deve se basear principalmente nas perspectivas próprias do paciente, envolvendo necessariamente uma gama de conteúdos que vão desde o bem-estar físico até a satisfação espiritual, por exemplo.

Em síntese, acreditamos que as novas classificações (IGDA, GLADP) que agregam os aspectos idiográficos, possam contribuir para a relativização do modelo biomédico na direção da vitalização do modelo biopsicossocial.

\section{Refletindo com as ilustrações clínicas}

Talita tem 77 anos, professora do nível médio aposentada, casada, vem para avaliação a partir do encaminhamento de sua psicanalista. Refere "palpitações, muita dificuldade para manter o sono” - acorda várias vezes durante a noite - 
sente-se "meio parada", com "fadiga” e ainda uma "agonia no estômago", "um bolo" (gesticula com a mão fechada, apontando para a altura do plexo solar).

Dos últimos acontecimentos que considera importantes em sua vida, relata tanto o descontentamento com a mudança ocorrida há quatro anos, após ter morado desde os quatro anos de idade num mesmo bairro, para um bairro "que não é 'família', que não tem o comércio perto, onde não se conhece ninguém” e ainda a cirurgia sofrida pelo marido, em função de um câncer na próstata.

Durante três anos fez uso de meio comprimido de Amineptina (antidepressivo), prescrito por um psiquiatra e, em janeiro último, resolveu parar de tomá-lo porque já não o encontrava nas farmácias (comprava a medicação sem receita médica). Cerca de vinte dias depois passou a sentir a sintomatologia acima. Conversou com sua atual médica clínica, que prescreveu então Citalopran 20mg/ dia (antidepressivo). Entretanto, Talita achou que era muito e, por conta própria, passou a tomar apenas meio comprimido. Não se considera ainda bem, "porque continuo a não dormir direito".

Algumas questões se apresentam:

A indicação e a prescrição de uma medicação antidepressiva realizadas sem que o paciente seja esclarecido sobre os riscos e os benefícios de seu uso, bem como sobre o tempo previsto de sua utilização, pode favorecer uma relação de adicção, seja psíquica, seja física - tolerância e dependência -, como deve ter sido o caso com a primeira prescrição da paciente. Aquela droga inclusive foi retirada do mercado por causar dependência física.

A indicação de antidepressivos pelos psiquiatras, clínicos, ginecologistas e médicos de outras especialidades baseada apenas no corolário de sinais e sintomas, ou seja, na evidência sintomatológica destituída de qualquer compreensão do funcionamento psíquico e do contexto familiar, social, cultural, pode lançar o paciente numa relação impensada e adictiva com o medicamento.

Expliquemos melhor. Observamos, conversando sem pressa com a paciente, que a mesma lida com todos os medicamentos que lhe são prescritos, inclusive os que a médica clínica lhe prescreve para a hipertensão, o hipotireodismo - tem possivelmente uma doença auto-imune, razão pelas qual está com os anticorpos tireoglobulina aumentados -, dessa mesma forma, isto é, diminui a dose por achar que "é demais". Sabemos que hipotireodismo, por exemplo, pode cursar com depressão, e que um paciente depressivo geralmente não adere aos tratamentos clínicos dada a sua desesperança, sua hipobulia. Talita pôde dizer que sua médica pouco conversa com ela sobre o uso e o porquê de tal ou qual indicação farmacológica, e geralmente faz a seguinte observação: "faça o que sua médica manda”, não lhe dando maiores explicações. Cabe ressaltar que se trata de atendimento clínico particular, e não conveniado e nem do SUS. 


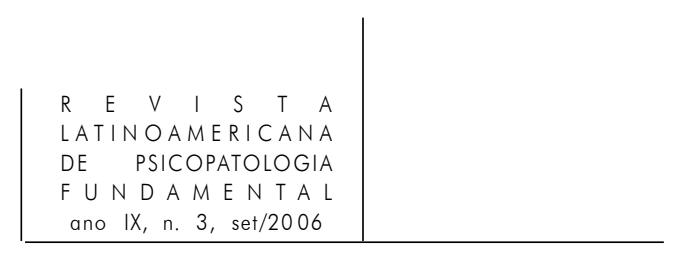

Neste caso a abordagem psiquiátrica se deu na direção de privilegiar o contexto das suas informações e, a partir daí, esclarecê-la, numa linguagem acessível, sobre o funcionamento do eixo neuroendócrino, da neurotransmissão e do mecanismo de feed-back para que ela pudesse entender a importância da utilização da medicação na posologia adequada além, é claro, da necessidade de conversar com seus médicos sobre o medo que sentia dos possíveis efeitos colaterais.

O antidepressivo prescrito pela médica clínica foi mantido, em função do seu perfil farmacodinâmico, que numa dose adequada pode ser uma boa escolha para os pacientes idosos. Essa decisão foi explicada à paciente que pareceu entender e concordou com a indicação. As informações permitiram que ela criasse um repertório para pensar sobre a sua "depressão", ou a sua "tristeza”, e sobre o seu modo de lidar com os medicamentos.

Os aspectos tais como resistência à mudança, acting, boicote ao tratamento, pulsão de morte, podem estar subjacentes às suas atitudes, mas ficam obscurecidos pela desinformação, pelo hábito, pela ação, que são endossados nos diversos atos médicos. Qual o seu verdadeiro pathos?

Provavelmente a paciente teve razões para apresentar um quadro de tristeza. Entretanto, essa tristeza parece ter sido logo medicalizada, decorrendo daí toda uma intervenção em sua neurotransmissão. Ou seja, não podemos afirmar, por exemplo, se o quadro apresentado deveu-se a uma síndrome de abstinência, a uma doença depressiva subjacente cujo tratamento foi abortado pelo uso irregular do antidepressivo, ou mesmo pela sua suspensão prematura.

Cerca de quarenta dias depois Talita se mostrava mais disposta, com sono regularizado, e sem sintomatologia somática. Nessa consulta a conversa pôde centrar-se na sua lida diária. Aventamos a possibilidade de reiniciar atividade física sob orientação, já que não tem conseguido realizar sozinha as caminhadas habituais, como uma tentativa de fazer laços, uma vez que "me sinto muito sozinha". A filha não mais precisa que ela tome conta do neto, o marido é "muito calado". "Sinto falta de me relacionar com outras pessoas, mas também sei que sou muito exigente".

Acreditamos que após essas abordagens seja facilitado o caminho para uma melhor compreensão da sua dinâmica psíquica, e que o trabalho com sua analista possa prosseguir na direção da sua verdade.

Máramo tem 46 anos, profissional da área de esportes, é casado, vive com a mulher e três filhinhos, veio para o atendimento movido pela conclusão a que chegou, junto com seu analista, de que não era mais possível que o mesmo continuasse a lhe prescrever os psicofármacos.

Queixava-se de "falta de energia”, "dificuldade para levantar da cama pela manhã", "tumulto na vida”, que definiu como "quero fazer tudo ao mesmo tempo 
e aí não consigo fazer nada”, "tenho baixa auto-estima e dependência emocional dos meus pais, embora seja casado, tenha filhos e trabalhe”, e insônia intermediária. Estava em uso de Paroxetina (antidepressivo) e Alprazolan (ansiolítico), sendo que, em relação a este último, apresentava sinais indicativos de tolerância e dependência: cada vez mais aumentava por conta própria o consumo do mesmo. Também neste caso, a dimensão tempo se impôs como elemento importante para a compreensão do seu contexto, do seu cotidiano, para o processo diagnóstico. Apesar de ser um profissional da área de esportes, e de sempre ter participado com prazer de competições esportistas, não estava mais fazendo qualquer exercício físico há muito tempo. Sabemos que a prática regular e orientada de exercícios físicos favorece, entre outras vantagens, a liberação de neurotransmissores importantes no combate à ansiedade, melhorando o sono e o desempenho diário das diversas tarefas.

Ficou claro no encontro clínico que ele precisava entender o que se passava do ponto de vista neuroendócrino, e da dependência ao benzodiazepínico que se configurava, na tentativa de propiciar-lhe uma abertura para outros caminhos que não o da repetição sem reflexão. Além do programa de "desmame” do ansiolítico, foi introduzido um outro antidepressivo (Sertralina), com as orientações quanto ao uso regular para a obtenção do efeito desejado, somado à regularidade e a freqüência mínima a um programa de atividade física, além do cuidado com o uso excessivo de bebidas escuras (café, mate, Coca-Cola, chá preto) à noite, já que disse perder o sono e ficar mais "ligado" por ocasião do uso das mesmas.

Após cinqüenta dias retorna para reavaliação. Sente-se mais "calmo, tolerante, paciente" e não mais apresentou ejaculação precoce (não referira essa queixa no atendimento inicial) e atualmente, com seis meses de tratamento psiquiátrico, já não faz mais uso do ansiolítico.

Máramo, que tem "uma mãe que não queria me ter e me puxa para baixo", já consegue diferenciar o estado de vazio interior, causado pela falta do olhar encantado da mãe (que pode ser o que chama de "impotência"), daquele estado de depressão, de "anedonia endógena". ${ }^{2}$ Este continuava a existir apesar do uso dos medicamentos prescritos anteriormente, provavelmente por representar um comportamento adictivo que visava preencher o vazio e aplacar uma grande ausência.

Podemos pensar com (Berlinck, 2000, p. 20-1) que o tratamento psicoterapêutico da depressão impõe um desafio ao analista: como conseqüência das enormes insuficiências e do desamparo vividos e sentidos pelo paciente com depressão, o analista pode passar a sofrer de anemia psíquica, desânimo,

2. Endon (origem, procedência) pode se manifestar física ou psiquicamente, conforme Tellenbach, citado por Berlinck, 2000, p. 16. 


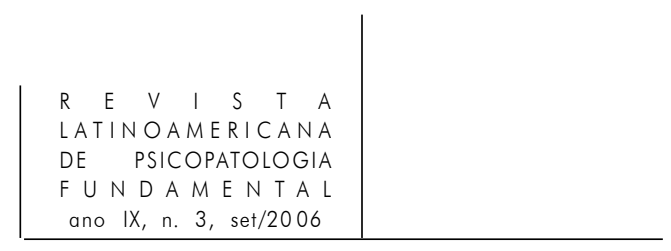

irritabilidade, fraqueza. Esse estado, o inverno transferencial, pode ter a sua travessia ameaçada caso o analista perca o contato com a própria depressividade. É provável que nesta situação clínica específica, o analista, diante de tão turbulento atravessar e por ser médico, tenha lançado mão da prescrição de antidepressivos e ansiolíticos como resposta à "falta de apetite de conteúdos psíquicos” (ibid., p. 20).

No entanto, a "falta de apetite" não prejudicou a avaliação de que se fazia necessária a contribuição da psiquiatria. Com a entrada desta profissional, foi reordenada a indicação, a escolha e a utilização dos psicofármacos. Juntamente com outras medidas direcionadas à saúde de forma global (qualidade de vida), isso acabou por favorecer à dupla analista/paciente a retomada da posição de trabalho analítico. A inércia narcísica começou a ser combatida pela via da interrogação metafórica, ou pela construção desta.

Estes casos ilustram, entre outras possibilidades, que os psicofármacos alteram o estado psicopatológico, tanto contribuindo para camuflar o verdadeiro pathos na radicalidade da sua singularidade quanto, numa outra perspectiva que leva em conta sobretudo o tempo, favorecendo que o sujeito se confronte com a verdade de seu sintoma.

Não será isso o que nos diz Máramo quando consegue diferenciar a sua “depressão” da sua "impotência para resolver as coisas”?

Outro aspecto a ser assinalado é aquele em que o encaminhamento para outro profissional significa a possibilidade de abrir um caminho, e não a transferência de responsabilidade. Estabelece-se um campo transferencial pela via do analista.

\section{O pharmakon}

Freud (1940a[1938]), com sua genialidade, já previa que estava reservada ao futuro a possibilidade de que substâncias químicas específicas exercessem influência direta nas quantidades de energia e na sua distribuição no aparelho mental. De fato, as substâncias químicas (psicofármacos) exercem influência nas quantidades de energia (neurotransmissores) que são o substrato do aparelho psíquico: sem cérebro não há mente, e vice-versa. Afinal, pathos é também somático. Freud (1933[1932], p. 188) ainda previu que no futuro seria possível o combate ao "aspecto quantitativo" das doenças através da "atuação dos hormônios”. Portanto, com as atuais contribuições e avanços das neurociências e da psicofarmacologia vemos a concretização daquilo que Freud intuiu a partir de sua acurada observação clínica. 
Mas como o adoecimento é desencadeado pela interação de diversos fatores, tanto constitucionais quanto adquiridos (resultantes da singularidade histórica) e acidentais, tem-se que o aspecto qualitativo, digamos assim, de qualquer adoecimento não poderá ficar dissociado do diagnóstico e da terapêutica.

Evocando Balint (1957) para quem o remédio mais usado em medicina é o próprio médico, podemos afirmar que para além e para aquém do efeito farmacológico de um dado medicamento existe o efeito da transferência, já que a relação médico-paciente é um encontro intersubjetivo com essa potência. É por essa razão que o medicamento é inseparável de uma ação subjetiva. Um exemplo disso é o efeito placebo. ${ }^{3}$

Assim, dois aspectos pelo menos devem ser considerados em relação à prescrição do medicamento: o efeito da droga em si (efeito farmacodinâmico) e o efeito transferencial, de forma que é preciso conhecer em ambos "a posologia, os efeitos colaterais e a toxicidade" como dito por Balint. Ainda é preciso lembrarmos que a palavra pharmakon (medicamento, droga) traz a ambigüidade daquilo que pode curar e daquilo que pode matar.

Nessa mesma direção observamos que também a palavra do médico tem eficácia terapêutica à medida que pode viabilizar uma pausa (um corte) na relação estereotipada (dependência) com a medicação, e introduzir a possibilidade de mudança discursiva.

Por outro lado, o ato de prescrever também dá ao paciente o reconhecimento da existência de uma doença que, por sua vez, pode produzir como efeito, em algumas situações clínicas, o endosso da não-implicação subjetiva do paciente no processo mórbido. Afinal, desde uma visão aristotélica, embora o homem não escolha as paixões (pathos pathológico), ele é o responsável pelas influências das mesmas em suas ações.

\section{E para onde vamos?}

Como dito anteriormente, a vocação clínica da psiquiatria vem desaparecendo em virtude do seu desejo de ocupar um lugar de ciência, sendo esta definida a partir do paradigma das ciências naturais. Sob esse olhar, o pathos é tomado de forma cartesiana, e não há lugar para a discursividade nem para o

3. Placebo, do latim “eu agradarei”, é uma preparação neutra, sem efeitos farmacológicos, ministrada em substituição a um medicamento, com a finalidade de suscitar ou controlar reações, geralmente psicológicas (Houaiss, 2001), é portanto, contingente. 


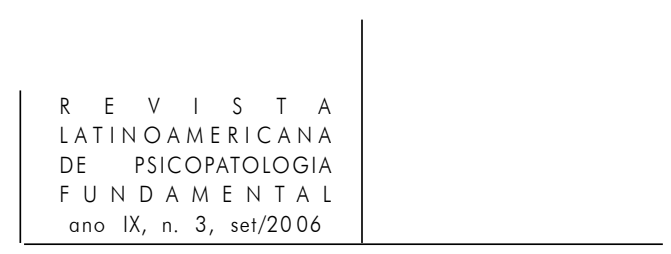

espanto como no pathos grego. Paradoxalmente, a psicanálise também corre esse mesmo risco do desaparecimento da sua prática, já que a invasão das "moléculas inteligentes", como conseqüência dos inegáveis avanços das neurociências, traz para o primeiro plano o cérebro com seus neurotransmissores objetivando-o como o único responsável por todas as ações, sentimentos, emoções do homem passíveis de serem "corrigidas". O eu fica assim submetido ao cérebro, e decididamente não há lugar para o sujeito da psicanálise, para a intersubjetividade.

Mas nem tudo está perdido!

O discurso da psicopatologia fundamental é eminentemente clínico, isto é, baseia-se no caso clínico ou na observação do fato clínico que ocorre na prática dos ocupantes de diversas posições, e leva em conta a subjetividade humana (Berlinck, 2002, p. 8). Consoante com isso, talvez possamos pensar que um dos operadores para que se retome a vocação clínica seja o processo de construção, apropriação e reconstrução da formação profissional dos sujeitos que fazem a clínica. A partir disso eles poderão transformar a si próprios e a sua prática (mudança subjetiva), mas desde que desenvolvam a capacidade de reflexão e o pensar crítico na tessitura da interlocução. Nessa medida, o enfoque se dá primordialmente na interdisciplinaridade onde seja possível incentivar as discussões clínicas através do diálogo com os diferentes saberes sobre o pathos. Cria-se assim o espaço de suporte para o não saber, já que as atuais apresentações pathicas, bem diferentes daquelas classicamente descritas, se constituem em desafios clínicos constantes. Urge uma abertura para a reinvenção do clinicar.

Tomando como base a afirmação de Fédida (2000, p. 81) de que a doença do século, a depressão, é hoje apenas uma noção, já que o seu uso generalizado acabou por banalizá-la - o que a coloca em vias de desaparecimento -, será nessa mesma direção que poderemos pensar como diagnosticá-la a partir dos novos sistemas classificatórios, e então talvez seja possível alçá-la a um lugar que não o da banalidade. Mas esta já é uma outra conversa!

\section{Referências}

Balint, Michel. The doctor, his patient and the illness. London: Pitman Medic Public, 1957.

BerLinck, Manoel Tosta e FÉdidA, Pierre. A clínica da depressão: questões atuais. Revista Latinoamericana de Psicopatologia Fundamental, São Paulo, v. III, n. 2, p. 9-25, jun. 2000.

DSM-IV TR. Critérios Diagnósticos. 4. ed. Porto Alegre: ArtMed, 2002. 


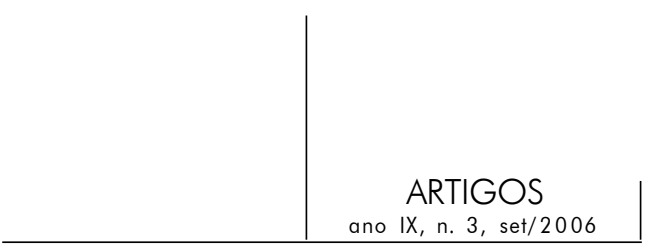

Editorial. Revista Latinoamericana de Psicopatologia Fundamental, São Paulo, v. III, n. 2, p. 8-11, jun. 2000.

FÉDIDA, Pierre. Modernité de la depresión. In: La depresión est-elle passée de mode? Paris: PUF, 2000. p. 81-93.

Freud, S. Edição Standard Brasileira das Obras Psicológicas Completas. 2. ed. Rio de Janeiro: Imago, 1987.

(1930 a[1929]). O mal-estar na civilização. In: Edição Standard Brasileira das Obras Psicológicas Completas. 2. ed. Rio de Janeiro: Imago, 1987. v. XXI.

(1933[1932]). Conferência XXXIV. Novas conferências introdutórias sobre psicanálise. In: Edição Standard Brasileira das Obras Psicológicas Completas. 2. ed. Rio de Janeiro: Imago, 1987. XXII.

(1940a[1938]). Esboço de psicanálise. In: Edição Standard Brasileira das Obras Psicológicas Completas. 2. ed. Rio de Janeiro: Imago, 1987. v. XXIII.

Houaiss, A. e Villar, M. S. Dicionário Houaiss da Língua Portuguesa. Rio de Janeiro: Objetiva, 2001.

Mezzich, Juan E. Values and comprehensive diagnosis. Journal of the World Psychiatry (WPA), New York: Masson, p. 91-2, jun. 2005.

Pereira, Mário Eduardo Costa. Formulações ideográficas do Diagnóstico. Jornal O Risco, publicação da Associação Mineira de Psiquiatria, v. XIII, n. 19, p. 14-6, out./2004.

SAdock, Benjamin J. \& SAdock, Virginia A. Kaplan \& Sadock’s Compreensive Textbook of Psychiatry. 8. ed. Philadelphia: Lippincott Williams \& Wilkins, 2005. 2 v.

SAurí, Jorge J. O que é diagnosticar em psiquiatria. São Paulo: Escuta, 2001.

\section{Resumos}

Este artigo es un convite a problematizar la indicación de drogas antidepresivas $y$, con eso, también problematizar el diagnóstico y el papel del psiquiatra como lo extraño-familiar en la relación psicoanalítica, o en la relación psicoterapéutica de base analítica, en el tiempo urgente de la actualidad. Resumidamente el artículo presenta las más recientes contribuciones sobre el diagnóstico abarcador, ideográfico, y emplea dos fragmentos clínicos para ilustrar el pathos antes y después del empleo de psicofármacos.

Palabras claves: Pharmakon, diagnóstico abarcador, interfaz, pathos 


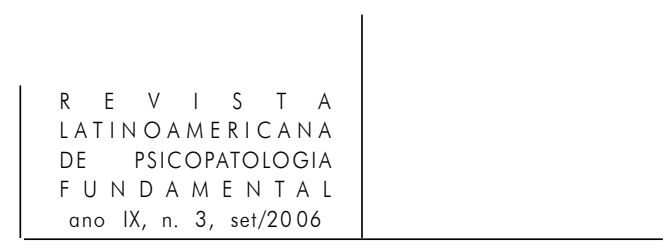

Cet article est une invitation à la problématization de l'indication des antidépresseurs et donc à la problématization du diagnostic et du rôle du psychiatre comme l'etrange-familial dans le rapport psychanalytique, ou dans le rapport psychothérapique de base analytique, dans le temps urgent de l'actualité. En abrégé il présente les plus récentes contributions à propos du diagnostic étendu, idiographique, et utilise deux vignettes cliniques à fin d'illustrer le pathos avant et après l'usage des substances psychoparmacologiques.

Mots clés: Pharmakon, diagnostic étendu, interface, pathos

This article questions the prescribing of antidepressant drugs and therefore also questions the diagnosis and the psychiatrist's role as the familiar-strange in a psychoanalytic relationship or in an analytically-based psychotherapeutic relationship in today's life of urgent time. The article briefly describes recent contributions in comprehensive, idiographic diagnosis, and uses two clinical vignettes to describe pathos before and after the use of psychopharmacological drugs.

Key words: Pharmakon, comprehensive diagnosis, interface, pathos 